\title{
A Randomized Controlled Trial of Team-Based Care: Impact of Physician-Pharmacist Collaboration on Uncontrolled Hypertension
}

\author{
Jacquelyn S. Hunt, Pharm D MS', Joseph Siemienczuk, MD², Ginger Pape, Pharm D', \\ Yelena Rozenfeld, $\mathrm{MPH}^{7}$, John Mackay, Pharm $D^{3}$, Benjamin H. LeBlanc, MD MBI', \\ and Daniel Touchette, Pharm D MA \\ 'Providence Physician Division, Beaverton, OR, USA; ${ }^{2}$ Providence Medical Group, Beaverton, OR, USA; ${ }^{3}$ University of North Carolina Hospital, \\ Chapel Hill, NC, USA; ${ }^{4}$ University of Illinois, Chicago, Chicago, IL, USA.
}

OBJECTIVE: Evaluate the effectiveness of collaborative management of hypertension by primary carepharmacist teams in community-based clinics.

STUDY DESIGN: A 12-month prospective, single-blind, randomized, controlled trial in the Providence Primary Care Research Network of patients with hypertension and uncontrolled blood pressure.

METHODS: As compared to usual primary care, intervention consisted of pharmacy practitioners participating in the active management of hypertension in the primary care office according to established collaborative treatment protocols. At baseline, there was no significant difference in blood pressure between groups. Primary outcome measures were the differences in mean systolic and diastolic blood pressures between arms at study end. Secondary measures included blood pressure goal attainment $(<140 / 90 \mathrm{mmHg})$, hypertension-related knowledge, medication adherence, home blood pressure monitoring, resource utilization, quality of life, and satisfaction.

RESULTS: A total of 463 subjects were enrolled ( $n=233$ control, $n=230$ intervention). Subjects receiving the intervention achieved significantly lower systolic $(\mathrm{p}=$ $0.007)$ and diastolic $(\mathrm{p}=0.002)$ blood pressures compared to control (137/75 $\mathrm{mmHg}$ vs. $143 / 78 \mathrm{mmHg})$. In addition, 62\% of intervention subjects achieved target blood pressure compared to $44 \%$ of control subjects $(\mathrm{p}=$ 0.003). The intervention group received more total office visits (7.2 vs. 4.9, p<0.0001), however had fewer physician visits (3.2 vs. $4.7, \mathrm{p}<0.0001)$ compared to control. Intervention subjects were prescribed more antihypertensive medications ( 2.7 vs. $2.4, \mathrm{p}=0.02$ ), but did not take more antihypertensive pills per day (2.4 vs. 2.5, $\mathrm{p}=0.87$ ). There were minimal differences between groups in hypertension-related knowledge, medication adherence, quality of life, or satisfaction.

The primary author had full access to all of the data in the study and takes responsibility for the integrity of the data and the accuracy of the data analysis.

Received April 15, 2008

Revised July 7, 2008

Accepted September 2, 2008

Published online September 25, 2008
CONCLUSIONS: Patients randomized to collaborative primary care-pharmacist hypertension management achieved significantly better blood pressure control compared to usual care with no difference in quality of life or satisfaction.

KEY WORDS: hypertension; randomized controlled study; pharmacist; primary care.

J Gen Intern Med 23(12):1966-72

DOI: $10.1007 / \mathrm{s} 11606-008-0791-\mathrm{x}$

(C) Society of General Internal Medicine 2008

\section{INTRODUCTION}

In 2007, the Association of Medical Colleges published "Recent Studies and Reports on Physician Shortages in the U.S." The projected shortage of physicians will be an estimated 55,000 to 200,000 by $2020 .^{2-4}$ The predicted mismatch between physician supply and patient demand is heavily influenced by the aging US population and the increased burden of chronic illness. Although some experts call for an increase in medical school admissions, others suggest this solution perpetuates past healthcare delivery design and ignores the opportunity to reconfigure the system based on the needs of the future. ${ }^{5}$ Specifically, Greenberg, et al. suggest that care of the aging population with widespread chronic illness should rely on coordination of care between physicians and non-physician healthcare professionals to facilitate improved disease management. ${ }^{5}$ However, there is a paucity of large, multi-site, randomized controlled studies assessing the value of allied healthcare professionals to help inform healthcare redesign.

Hypertension is an appropriate target for team-based disease management based on its high prevalence (affects 50 million Americans) and poor disease control (66\% of patients fail to achieve a target $<140 / 90 \mathrm{mmHg}){ }^{6}$ Although papers describing the potential role of clinical pharmacists in the care of hypertension date back more than 30 years, ${ }^{7}$ this approach has not been widely disseminated outside of closed delivery systems, such as the Veterans Administration. Optimal management of hypertension relies on patient education, encouragement of self-management and lifestyle modification, use of antihypertensive agents and blood pressure monitoring. ${ }^{6}$ When patients do not reach target blood pressure, regular follow-up with a vigorous stepped approach to antihyperten- 
sive therapy is recommended. ${ }^{8}$ These elements of hypertension management are within the scope and training of all Doctors of Pharmacy completing accredited residency training in primary care. ${ }^{9}$ A systematic review evaluating pharmacists in expanded patient care roles found improved outcomes in chronic health conditions, including hypertension. ${ }^{10}$

The purpose of this study was to address important evidence gaps by assessing the impact of co-located physician-pharmacist team-based care on blood pressure control, quality of life and patient satisfaction in patients cared for by all physicians practicing in multiple community-based clinics over a 1-year period.

\section{METHODS}

This study was a 12-month, single-blind, randomized, controlled study, approved by the organizational institutional review board.

Study Site and Population. The study was conducted within the Providence Primary Care Research Network in Oregon, which is part of a not-for-profit integrated delivery system. All Network community-based primary care clinics were included $(n=9)$, with the exception of academic teaching clinics $(n=4)$. Participating clinics comprised approximately 80 physicians caring for 110,000 patients of mixed insurance status.

To identify candidates with known hypertension and uncontrolled blood pressure, the Network's electronic medical record (EMR) database was queried (February 2000) for patients with an office visit within the past 2 years, a problem list entry of hypertension (ICD-9 of 410.*), and a last systolic blood pressure $\geq 160 \mathrm{mmHg}$ and/or a last diastolic blood pressure $\geq 100 \mathrm{mmHg}$. Patients with mildly uncontrolled blood pressure (140-159/90-99 $\mathrm{mmHg}$ ) were offered participation in a parallel study evaluating mailed patient self-management materials (data published elsewhere). ${ }^{11}$

Subjects were excluded if there was no blood pressure reading in the chart in the previous 2 years, they had attended a visit with a pharmacy practitioner in the previous 6 months, or they had transferred care out of the Network.

All eligible candidates received a mailed invitation for participation. Interested candidates provided consent by return postcard or phone. At the time consent was received by research staff, subjects were randomly assigned, with equal allocation and without restrictions, to intervention or control using a computer-generated random sequence. Based on the nature of the intervention, participant blinding was not possible. All subjects were mailed hypertension educational materials ${ }^{11}$ in order to assure similar baseline awareness of hypertension self-management principles between groups.

Intervention. Subjects allocated to usual care were instructed to continue their normal schedule of medical care. The primary care physician was also provided a list of subjects allocated to usual care. Out of concern, subjects with an entry $\mathrm{BP} \geq 180$ / $110 \mathrm{mmHg}$, based on last measurement in the EMR, were scheduled for an appointment with their primary care provider if a future appointment did not already exist.

Subjects allocated to the intervention were scheduled for an appointment in their primary care clinic with any one of five
Network-employed pharmacy practitioners. Each pharmacist had a post-baccalaureate doctor of pharmacy degree, 1 to 2 years of ambulatory medicine residency training, and was board certified in pharmacotherapy. No additional training was provided in preparation for this study. During the initial visit, pharmacists described the physician-pharmacist collaborative model of care. Consistent with Network-approved collaborative hypertension management guidelines, the pharmacists reviewed subjects' medications and lifestyle habits, assessed vital signs, screened for adverse drug reactions, identified barriers to adherence, provided education, optimized the antihypertensive regimen, and scheduled follow-up appointments as judged necessary. Antihypertensive regimen optimization included alterations in antihypertensive regimens to titrate the dose of an existing medication, add a new agent, switch a medication, or consolidate antihypertensive therapy. The pharmacist had access to patients' medical records to assist medication selection and dosing, as well as access to the primary care physician (PCP) to discuss the hypertension treatment plan or other medical issues as needed. Following each interaction, a note was documented in the EMR and forwarded to the PCP for approval and co-signature.

\section{Outcome Measures}

Clinical. The primary outcome was the difference in mean systolic and diastolic blood pressures between the team-based care arm (intervention) and the usual care arm (control) at study end. Effectiveness of hypertension management was also evaluated as the proportion of subjects in each group achieving a target blood pressure $<140 / 90 \mathrm{mmHg}$. At study end, subjects attended open clinic sessions in which blood pressure was assessed by registered nurses blinded to subjects' randomization allocation. Three blood pressure measurements were taken according to study protocol using an appropriately sized cuff and standard mercury sphygmomanometer after the subject had been sitting quietly for at least $5 \mathrm{~min}$ with no less than 5 min between measurements. The mean of the second and third pressures was used for analysis. If a subject failed to attend the exit visit despite multiple contact attempts (i.e., drop out), a chart review was conducted to extract the last available clinic blood pressure for intention-to-treat (ITT) analysis.

Self-management. Patient self-management knowledge and behavior measures were assessed by a self-administered questionnaire completed at baseline and exit study visit. An internally designed ten-item instrument was tested for readability, face and content validity with local experts, and for internal validity in a sample of patients. ${ }^{11}$ An aggregate score was calculated based on the number of correctly answered questions. Assessment of medication adherence consisted of four validated patient self-reported questions. ${ }^{12}$ Subjects were also asked whether they used a home blood pressure monitoring device and, if so, whether they recorded their readings.

Resource Utilization. Healthcare utilization information was collected by chart audit during the period of time from subject consent through the date of the exit visit. Information on the number and purpose for each office visit with a primary 
care provider and/or a pharmacist was extracted. This information was reported in three categories: (1) primary care provider, (2) pharmacist, and (3) the sum of total clinic visits. Information was also collected on antihypertensive use including drug class(es), generic status, dosages per day, and number of pills per day.

Quality of Life and Satisfaction. Subjects' health status was evaluated at the exit visit using the Medical Outcomes Study SF-36 survey reporting scaled results for the eight domains, as well as physical and mental health composite scores. ${ }^{13}$ In addition, subjects were asked to rate their satisfaction with components of healthcare delivery and hypertension treatment. The general healthcare domain included six questions about satisfaction with provider, health plan, and care delivery (e.g., access, service). The hypertension-specific domain included five questions inquiring about satisfaction with explanations of hypertension, antihypertensive medications, cost of antihypertensive medications, time spent discussing hypertension, and satisfaction with hypertension monitoring.

Statistical Analysis. A sample size of 151 subjects per arm was required to detect a $3-\mathrm{mmHg}$ difference in mean systolic and diastolic blood pressures between intervention and control groups for $90 \%$ power at a significance level of $\mathrm{p}<0.05$ (twosided), assuming a standard deviation for systolic and diastolic blood pressures of $8 \mathrm{mmHg}$.

The primary outcomes of systolic and diastolic blood pressure between groups at the study end were compared using unpaired t-tests. Other continuous data were described by mean (standard deviation) and were compared using paired t-test for within-group baseline-to-final assessment comparisons and unpaired t-tests for between-group analysis. Association between continuous variables was measured using correlation analysis. Categorical data were described by percentages and were compared by chi-square tests with continuity correction or Fisher's exact test, as appropriate. Repeated measures analyses of variance were used to evaluate continuous variables such as quality-of-life composite scores, hypertension knowledge, and patient satisfaction. The Mann-Whitney U test was used for between-group comparisons for variables that were not normally distributed. The Wilcoxon signed-ranks test for paired samples was used for within-group comparisons. ${ }^{14}$ The significance level was set at 0.05. All analyses were completed using SAS version 9.1. ${ }^{15}$

\section{RESULTS}

A total of 2,901 candidates were identified as eligible and mailed an invitation to participate. Of the 463 subjects consenting to participate (16\% response rate), 233 were allocated to usual care, and 230 were allocated to team-based care (Fig. 1). The intervention and control arms were comparable with respect to age, gender, education, insurance, body mass index, smoking status, prevalence of chronic illness, and baseline blood pressure with the exception of history of stroke (Table 1). As seen in Fig. 1, a total of 191 subjects (41\%) withdrew from the study following randomization, 88 (38.3\%) from the intervention arm and $103(44.2 \%)$ from the control arm. Of subjects unavailable at the exit visit, all had documented blood pressures in the chart, with the exception of seven subjects ( $n=4$ control; $n=3$ intervention), in which case the last clinic blood pressures were carried forward. Detailed analyses published elsewhere demonstrate that the groups remained comparable despite withdrawal. ${ }^{16}$

Clinical. Between-group analysis revealed significant differences in mean systolic $(\Delta=6 \mathrm{mmHg}, \mathrm{p}=0.007)$ and diastolic $(\Delta=$ $3 \mathrm{mmHg}, \mathrm{p}=0.003$ ) blood pressures between groups at study end with subjects receiving team-based care achieving lower systolic and diastolic blood pressures as compared to control (Table 2). In addition, 62\% (88/142) of intervention subjects had a blood pressure $<140 / 90 \mathrm{mmHg}$ at the exit visit as compared to $44 \%(57 / 130)$ of control subjects $(p=0.003)$. The odds of achieving blood pressure target in the intervention group were 2.08 times higher than the control group (95\% CI=1.29-3.38). These differences remained significant when data were assessed by intention-to-treat analysis.

Self-management. At study end, there was no difference in hypertension-related knowledge scores between study arms with a mean score of $7.5(\mathrm{SD}=1.86)$ in the control arm and 7.9 $(\mathrm{SD}=1.65)$ in the intervention arm $(\mathrm{p}=0.27)$. There was a statistically significant interaction between time and group $(p=0.0013)$ such that hypertension-related knowledge increased in the intervention arm and decreased in the control arm from study start to end. Analysis was completed to evaluate the relationship between hypertension knowledge and achievement of blood pressure target. Only in the intervention arm, there was a significant difference in hypertension knowledge between those subjects who achieved the target blood pressure (mean score $=8.2$ ) and those who did not meet target (mean score $=7.4, \mathrm{p}=0.03$ ).

There was no difference between groups at study end in the proportion of subjects reporting high medication adherence [67\% (95/142) intervention vs. 69\% (90/130) control, $p=0.77]$. Within-group analysis indicated no significant increase in adherence from baseline to final assessment in the control group $(\mathrm{p}=0.52)$. Although subjects receiving the intervention demonstrated an increase in the high adherence category from baseline (61\% vs. 67\%), the difference was not statistically significant $(p=0.08)$. High medication adherence failed to predict hypertension goal attainment in either group. At study end, subjects in the intervention arm reported owning a home blood pressure monitoring device more frequently than control subjects [70\% (70/99) vs. 51\% (46/91), p=0.007]. A higher proportion of subjects in the intervention arm also reported recording their home blood pressures in a logbook as compared to control [80\% (56/70) vs. 53\% (24/46), p=0.002].

Resource Utilization. The total number of clinic visits (physician + pharmacist) was significantly higher in the intervention arm as compared to control (Table 3). However, the number of physician visits was significantly lower in the intervention arm (3.2 vs. 4.7, $\mathrm{p}<0.0001)$. The pharmacy visits $(\mathrm{n}=26)$ in the control arm represented by six subjects were cases where the physician requested and received a pharmacy consultation for hypertension. The number of office visits was not statistically associated with systolic blood pressure in either study arm 


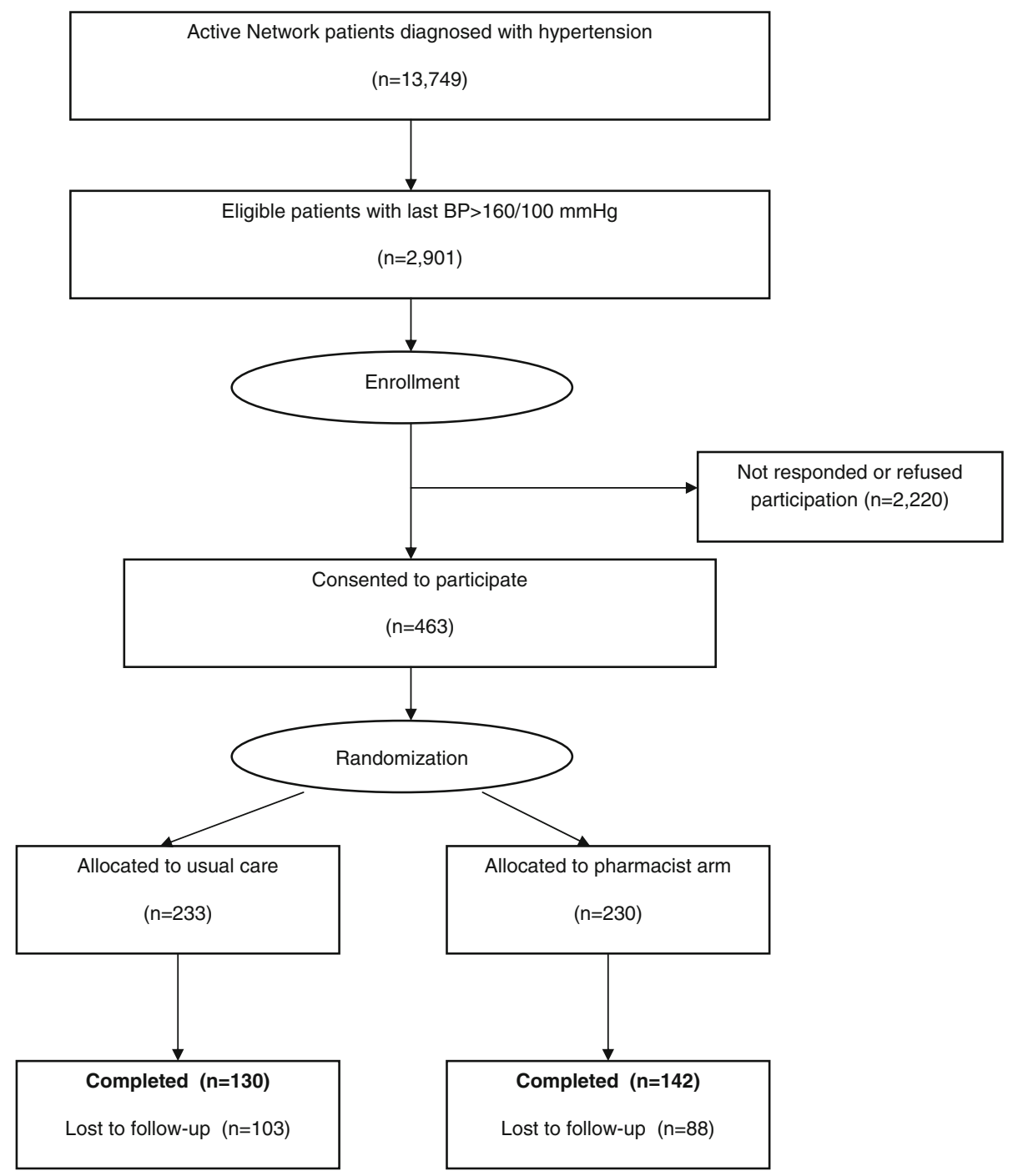

Figure 1. Patient population eligibility, participation, and randomization flow diagram.

(intervention: $r=0.16, \mathrm{p}=0.06$ and control: $r=-0.1, \mathrm{p}=0.22$ ), but was negatively associated with diastolic blood pressure in both study arms (intervention: $r=-0.22, \mathrm{p}=0.01$ and control: $r=-0.18$, $\mathrm{p}=0.04$ ).

The number of antihypertensive medications increased significantly in both groups as compared to baseline. Although subjects in the intervention arm were prescribed a higher number of antihypertensive medications, there was a small but insignificant decrease in the daily pill burden of this group (Table 3). This decrease is explained by a higher penetration of combined dosage forms in the intervention arm. The intervention group was also significantly more likely to utilize generic antihypertensive medications.

Quality of Life and Satisfaction. There were no significant differences between groups with respect to subjects' quality of life at follow-up with the exception of the general health domain $(\mathrm{p}=0.01)$, in which scores were slightly higher in the control group compared to intervention (Table 4). Subjects in both groups were highly satisfied with the hypertension care received. The overall satisfaction was 8.5 in the usual care group compared to 8.6 in the pharmacy group $(\mathrm{p}=0.75)$. There was no significant difference between groups in any of the 11 satisfaction measures and no association between satisfaction and blood pressure goal attainment $(\mathrm{p}=0.4)$.

\section{DISCUSSION}

In this study, subjects cared for in the physician-pharmacist team model were $40 \%$ more likely to achieve their goal blood pressure compared to those cared for by their physician alone. Among middle-aged patients (i.e., 60-69 years), the 6-mmHg difference in systolic blood pressure observed in this study would be expected to yield a $22 \%$ reduction in stroke mortality and a $17 \%$ reduction in mortality from ischemic heart disease. ${ }^{17}$ Thus, inclusion of pharmacy practitioners on the primary care team represents one possible strategy to address this important public health issue.

Alternatively, elucidating the underlying mechanisms by which the team-based model achieved superior outcomes in 
Table 1. Baseline Demographics

\begin{tabular}{|c|c|c|c|}
\hline & $\begin{array}{l}\text { Usual care } \\
(n=233)\end{array}$ & $\begin{array}{l}\text { Intervention } \\
(n=230)\end{array}$ & $\begin{array}{l}\mathrm{p}- \\
\text { value }\end{array}$ \\
\hline Age-mean (SD) ${ }^{1}$ & $68(13)$ & $68(12)$ & 0.86 \\
\hline Gender, male-n (\%) & 79 (34) & $85(37)$ & 0.46 \\
\hline Insurance-n (\%) & & & 0.20 \\
\hline Commercial & $72(31)$ & $84(37)$ & \\
\hline Medicare or Medicaid & $161(69)$ & $146(63)$ & \\
\hline $\begin{array}{l}\text { Education, college } \\
\text { education-n (\%) }\end{array}$ & $65(28)$ & $64(28)$ & 0.56 \\
\hline Current smoker-n (\%) & $17(7)$ & $20(9)$ & 0.58 \\
\hline Body mass index-mean (SD) & $30(6)$ & $29(6)$ & 0.40 \\
\hline \multicolumn{4}{|l|}{ Co-morbidities-n (\%) } \\
\hline Asthma or COPD & $27(12)$ & $27(12)$ & 0.96 \\
\hline Diabetes & $57(25)$ & $59(26)$ & 0.77 \\
\hline History of stroke & $6(3)$ & $15(7)$ & 0.04 \\
\hline Coronary artery disease & $43(18)$ & $46(20)$ & 0.67 \\
\hline Renal impairment & $6(3)$ & $8(3)$ & 0.57 \\
\hline $\begin{array}{l}\text { One or more chronic } \\
\text { conditions }\end{array}$ & $103(44)$ & $111(48)$ & 0.38 \\
\hline $\begin{array}{l}\text { Baseline systolic blood } \\
\text { pressure*-mean (SD) }^{*}\end{array}$ & $174(15)$ & 173 (15) & 0.43 \\
\hline $\begin{array}{c}\text { Baseline diastolic blood } \\
\text { pressure*-mean (SD) }\end{array}$ & $92(14)$ & $90(14)$ & 0.21 \\
\hline
\end{tabular}

${ }^{1} \mathrm{SD}=$ standard deviation

*Data acquired from the EMR based on last available blood pressure value in the 24 months prior to study start

this study may facilitate modification of physician practice within the current healthcare delivery model. National guidelines recommend combination therapy as a means to intensify treatment without increased complexity, a practice implemented in higher frequency in the team-based arm. ${ }^{6}$ Patient costsharing is another factor in medication adherence. ${ }^{8,18}$ Although this study did not assess patient medication cost-share, the higher generic prescribing rate in the collaborative arm can be considered a surrogate outcome for cost.

Given the recent findings by Lee et al. ${ }^{19}$, it was somewhat surprising that our study found no difference between arms in self-reported medication adherence. The four-item selfreported questionnaire may not have been sensitive enough

Table 2. Blood Pressure Results

\begin{tabular}{llll}
\hline \hline & $\begin{array}{l}\text { Usual care } \\
(n=130)\end{array}$ & $\begin{array}{l}\text { Intervention } \\
(\mathrm{n}=142)\end{array}$ & $\begin{array}{l}\mathrm{p}- \\
\text { value }\end{array}$ \\
\hline $\begin{array}{c}\text { Systolic blood pressure } \\
\text { Result available from study } \\
\text { exit visit-mean (SD) }\end{array}$ & $143(18)$ & $137(17)$ & 0.007 \\
$\begin{array}{c}\text { ITT }^{2} \text { (includes last value } \\
\text { carried forward)-mean (SD) }\end{array}$ & $148(22)$ & $142(19)$ & 0.002 \\
$\begin{array}{c}\text { Diastolic blood pressure } \\
\text { Result available from study } \\
\quad \text { exit visit-mean (SD) }\end{array}$ & $78(11)$ & $75(9)$ & 0.003 \\
$\begin{array}{c}\text { ITT (includes last value } \\
\text { carried forward)-mean (SD) }\end{array}$ & $80(12)$ & $77(10)$ & 0.003 \\
$\begin{array}{c}\text { Goal attainment <140/90 } \\
\text { mmHg }\end{array}$ & & & \\
$\begin{array}{c}\text { Result available from } \\
\text { study exit visit-\% (N/D) }\end{array}$ & $44(57 / 130)$ & $62(88 / 142)$ & 0.003 \\
$\begin{array}{c}\text { ITT (includes last value } \\
\text { carried forward)-\% (N/D) }\end{array}$ & $42(97 / 233)$ & $54(125 / 230)$ & 0.005 \\
\hline
\end{tabular}

2 Intention-to-treat

$3 \mathrm{~N}=$ numerator, $D=$ denominator
Table 3. Utilization of Office Visits and Antihypertensive Medications

\begin{tabular}{|c|c|c|c|}
\hline & $\begin{array}{l}\text { Usual care } \\
(n=130)\end{array}$ & $\begin{array}{l}\text { Intervention } \\
(n=142)\end{array}$ & $\mathrm{p}$-value \\
\hline \multicolumn{4}{|l|}{ Visits } \\
\hline \multicolumn{4}{|l|}{ Office visits-mean (SD) } \\
\hline PCP visits per patient & $4.7(3.1)$ & $3.2(2.7)$ & $<0.0001$ \\
\hline $\begin{array}{l}\text { Pharmacist visits } \\
\text { per patient }\end{array}$ & $0.2(0.8)$ & $4.0(2.3)$ & $<0.0001$ \\
\hline Total visits per patient & $4.9(3.3)$ & $7.2(3.3)$ & $<0.0001$ \\
\hline \multicolumn{4}{|l|}{$\begin{array}{l}\text { Hypertension-related } \\
\text { visits-mean (SD) }\end{array}$} \\
\hline PCP visits per patient & $2.9(2.2)$ & $1.8(1.7)$ & $<0.0001$ \\
\hline $\begin{array}{l}\text { Pharmacists visits } \\
\text { per patient }\end{array}$ & $0.2(0.8)$ & $4.0(2.3)$ & $<0.0001$ \\
\hline Total visits per patient & $3.1(2.4)$ & $5.8(2.6)$ & $<0.0001$ \\
\hline \multicolumn{4}{|l|}{ Pharmacotherapy } \\
\hline $\begin{array}{l}\text { Antihypertensive } \\
\text { medications per patient- } \\
\text { mean (SD) }\end{array}$ & $2.4(1.1)$ & $2.7(1.2)$ & 0.02 \\
\hline $\begin{array}{l}\text { Pills per patient per day- } \\
\text { mean (SD) }\end{array}$ & $2.5(1.7)$ & $2.4(1.6)$ & 0.87 \\
\hline $\begin{array}{l}\text { Use of generic } \\
\text { antihypertensive agent- } \%\end{array}$ & 39.7 & 50.7 & 0.008 \\
\hline
\end{tabular}

to detect a difference if it did exist. Subjects in the team-based care intervention appeared more engaged in the management of their hypertension as indicated by increased home blood pressure monitoring. Another commonly proposed mechanism, not evaluated in this study, is time spent with the patient during each visit. Moreover, physicians in the study were undoubtedly confronted with multiple health issues, while in the team-based model pharmacists were able to focus more narrowly on management of hypertension.

Although subjects in the intervention arm were prescribed a higher number of antihypertensive medications, our study found a negligible impact of the team-based care on patient quality of life and satisfaction. Other evidence suggests that the impact of similar pharmacy interventions on patient quality of life represents a neutral ${ }^{20,21}$ to positive effect. ${ }^{22-24}$ These results dispel the notion that introducing pharmacists

Table 4. MOS SF-36 Health-Related Quality of Life

\begin{tabular}{lccc}
\hline \hline & $\begin{array}{l}\text { Usual care } \\
(n=130)\end{array}$ & $\begin{array}{l}\text { Intervention } \\
(n=142)\end{array}$ & p-value \\
\hline Quality of life & Mean (SD) & Mean (SD) & \\
Physical functioning & $42(12)$ & $44(11)$ & 0.33 \\
Role limitation, physical & $49(7)$ & $48(7)$ & 0.49 \\
Bodily pain & $33(11)$ & $32(10)$ & 0.43 \\
General health & $44(6)$ & $42(6)$ & $0.01^{*}$ \\
Vitality (energy and fatigue) & $49(5)$ & $48(5)$ & 0.20 \\
Social functioning & $35(6)$ & $35(5)$ & 0.70 \\
Role limitations, emotional & $48(12)$ & $49(11)$ & 0.32 \\
Mental health & $42(6)$ & $44(6)$ & 0.15 \\
Physical component & $42(6)$ & $41(6)$ & 0.12 \\
$\quad$ summary (PCS) & $44(6)$ & $45(6)$ & 0.16 \\
Mental component & & & \\
$\quad$ summary (MCS) & & & \\
\hline
\end{tabular}

Significant at $p<0.05$ 
into primary care-based chronic disease management risks jeopardizing the physician-patient relationship.

The fundamental requirements for successful generalization of this strategy include an adequate workforce of trained pharmacy practitioners and third party reimbursement. Given shortfalls in effectiveness of the current healthcare delivery model, ${ }^{25}$ projected physician shortages, and the preponderance of evidence demonstrating improved outcomes when pharmacists actively participate on patients' care team, ${ }^{10}$ the inclusion of pharmacists as healthcare providers eligible for reimbursement for cognitive services warrants serious consideration.

The results of this study add to a growing body of literature demonstrating the positive effect of physician-pharmacist team-based management of hypertension. ${ }^{7,21,23,26-28}$ This study has several strengths, including (1) prospective, randomized, controlled design with evaluator blinding, (2) large community-based patient population with mixed insurance, (3) multi-site intervention including all physicians practicing in nine clinics, (4) involvement of multiple pharmacy practitioners, (5) 12-month study duration, and (6) inclusion of clinical, patient self-management, economic, quality of life, and satisfaction outcome measures.

This study is further unique compared to other published randomized controlled trials evaluating pharmacists' role in hypertension management. ${ }^{7,21,23,26,27,29}$ In contrast to most published studies, with the exception of a study conducted in a VA setting, ${ }^{28}$ the pharmacists in this study were empowered to alter the antihypertensive regimen, according to guidelines, without consulting the physician in advance. Unlike the VA study, where pharmacists were located in a separate pharmacist-run hypertension clinic, ${ }^{28}$ our study evaluated pharmacists co-located in the primary care clinic. In this more teamoriented setting, pharmacists were able to quickly consult the physician for cases involving complex co-morbidities or the need for departure from routine guidelines, possibly improving efficiency, communication, and trust.

In this study, randomization at the patient level, as opposed to physician or clinic, may have resulted in contamination bias. Physicians in the study cared for patients in both groups and, further, co-signed the chart note following every pharmacist-patient interaction. In addition, at the request of the physician, six subjects in the control group received pharmacy consultation during the study. Although contamination was considered during study design, investigators recognized that it would conservatively represent bias toward the null hypothesis. Further, subjects in the usual care arm were offered active interventions. These interventions included (1) mailed patient educational information, ${ }^{11}$ (2) patient prompts where there was not a scheduled appointment, and (3) physician prompts for patients with elevated blood pressure. These interventions may also have blunted the difference in outcomes between arms.

In this study, we observed that only $16 \%$ of patients with an active medical record who were solicited to participate via a mailed invitation responded and subsequently consented. In practice, unlike the screening and enrollment methods employed in the study, patients are typically seen by a clinical pharmacy practitioner following a direct verbal referral by the PCP. This more traditional referral process might be expected to yield a higher screening-to-enrollment ratio relative to the low-touch methodology used here. Effective referral and enrollment methodologies, as well as patient acceptance of team-based care involving a pharmacy practitioner, merit further investigation.

The subject withdrawal rate observed in this study is similar to the rate reported in other hypertension management studies. ${ }^{21,23,27}$ This study used a low intensity screening and consent process, which might contribute to the high withdrawal rate. Analyses published elsewhere demonstrate that the high withdrawal rate observed in this study did not likely create an important imbalance in between-group subject characteristics for those who completed the study. ${ }^{16}$ When subjects who completed and withdrew from the study were compared, the only factor significantly associated with a higher withdrawal rate was enrollment in commercial insurance. The external validity of this study was also not affected by subject dropout and may even have been enhanced due to the naturalistic subject recruitment strategy. Regardless of the type of analysis conducted (analysis of subjects completing the study or last value carried forward for all enrolled subjects), a similar reduction in blood pressure was observed in the intervention group.

\section{CONCLUSION}

Involvement of pharmacy practitioners in management of hypertension significantly improves blood pressure control. This improvement is accomplished without apparent increased complexity or cost to the antihypertensive medication regimen. This team-based model of hypertension management results in an increase in total office visits, with a significant decrease in the number of physician visits. Finally, addition of a pharmacy practitioner to the healthcare team does not significantly alter patient quality of life or satisfaction.

Acknowledgement: We would like to extend our thank you to Kristina Butler, Pharm.D., BCPS (Providence Physician Division, Department of Pharmacy) for providing patient care services during this study.

Grant Support: Grant support from Boehringer Ingelheim was used to fund the cost of the educational mailings and the conduction of the study.

Conflict of Interest: All data collection, analysis, and reporting were conducted by the study investigators and the Providence research staff. The investigators report no other conflict of interest.

Corresponding Author: Jacquelyn S. Hunt, Pharm D MS; Providence Physician Division, 3601 SW Murray Blvd, Ste 45, Beaverton, OR 97005, USA (e-mail: jacquelyn.hunt@providence.org).

\section{REFERENCES}

1. Association of American Medical Colleges. Recent Studies and Reports on Physician Shortages in the U.S. Association of American Medical Colleges; 2007 August.

2. Merrit J, Hawkins J, Miller P. Will the last physician in america please turn off the lights? A look at America's looming doctor shortage. Irving: The MHA Group; 2004.

3. Health Resources and Services and Administration (HRSA). Physician Supply and Demand: Projections to 2020. Health Resources and Services and Administration (HRSA); 2006 October. 
4. Council on Graduate Medical Education. Physician Workforce Policy Guidelines for the U.S. for 2000-2020. US Department of Health and Human Services; 2005.

5. Greenberg JO, Greenberg H. More physicians are not the answer. Am J Cardiol. 2007;99(10):1476-8, May 15.

6. Chobanian AV, Bakris GL, Black HR, et al. Seventh report of the Joint National Committee on Prevention, Detection, Evaluation, and Treatment of High Blood Pressure.[see comment]. Hypertension. 2003;42(6):1206-52, December.

7. McKenney JM, Slining JM, Henderson HR, Devins D, Barr M. The effect of clinical pharmacy services on patients with essential hypertension. Circulation. 1973;48(5):1104-11, November.

8. Schroeder K, Fahey T, Ebrahim $\mathbf{S}$. How can we improve adherence to blood pressure-lowering medication in ambulatory care? Systematic review of randomized controlled trials. [Review] [55 refs]. Arch Intern Med. 2004;164(7):722-32, April 12.

9. American Society of Health-System Pharmacists. ASHP statement on the pharmacist's role in primary care. Am J Health Syst Pharm. 1999;56:16657.

10. Beney J, Bero LA, Bond C. Expanding the roles of outpatient pharmacists: effects on health services utilisation, costs, and patient outcomes. Cochrane Database Syst Rev. 2000;3:CD000336.

11. Hunt JS, Siemienczuk J, Touchette D, Payne N. Impact of educational mailing on the blood pressure of primary care patients with mild hypertension. J Gen Intern Med. 2004;19(9):925-30, September.

12. Morisky DE, Green LW, Levine DM. Concurrent and predictive validity of a self-reported measure of medication adherence. Med Care. 1986;24 (1):67-74, January.

13. Ware JE, Kosinski M. SF-36 physical and mental health summary scales: a manual for users of version 1. 2nd ed. Lincoln, RI: QualMetric Incorporated; 2001.

14. Dawson-Saunders B, Trapp RG. Basic and Clinical Biostatistics. Second ed. Norwalk, CT: Appleton \& Lange.; 1994.

15. SAS Institute Inc. SAS/STAT User's Guide, Version 9.1. 2003. Cary, NC, SAS Institute. Ref Type: Generic

16. Rozenfeld Y, Hunt JS. Effect of patient withdrawal on a study evaluating pharmacist management of hypertension. Pharmacotherapy. 2006;26(11):1565-71, November.

17. Lewington S, Clarke R, Gizilbash N, Peto R, Collins R. Age-specific relevance of usual blood pressure to vascular mortality: a meta-analysis of individual data for 1 million adults in 61 prospective studies. Lancet 2002;360(9349): 1903-13, December 14

18. Osterberg L, Blaschke T. Adherence to medication.[see comment] [Review] [127 refs]. N Engl J Med. 2005;353(5):487-97, August 4.

19. Lee JK, Grace KA, Taylor AJ. Effect of a pharmacy care program on medication adherence and persistence, blood pressure, and low-density lipoprotein cholesterol: A randomized controlled trial. JAMA. 2006;296 (21):2614-6, December 6.

20. Erickson SR, Slaughter R, Halapy H. Pharmacists' ability to influence outcomes of hypertension therapy. Pharmacotherapy. 1997;17(1):140-7, January.

21. Mehos BM, Saseen JJ, MacLaughlin EJ. Effect of pharmacist intervention and initiation of home blood pressure monitoring in patients with uncontrolled hypertension. Pharmacotherapy. 2000;20(11):1384-9, November.

22. Carter BL, Barnette DJ, Chrischilles E, Mazzotti GJ, Asali ZJ. Evaluation of hypertensive patients after care provided by community pharmacists in a rural setting. Pharmacotherapy. 1997;17(6):1274-85, November.

23. Okamoto MP, Nakahiro RK. Pharmacoeconomic evaluation of a pharmacist-managed hypertension clinic. Pharmacotherapy. 2001;21 (11):1337-44, November.

24. Carter BL, Malone DC, Billups SJ, et al. Interpreting the findings of the IMPROVE study. Am J Health Syst Pharm. 2001;58(14):1330-7, July 15.

25. Institute of Medicine. Crossing the Quality Chasm: A new Health System for the 21st Century. Washington, DC: National Academy of Sciences: 2001 .

26. Bogden PE, Abbott RD, Williamson P, Onopa JK, Koontz LM. Comparing standard care with a physician and pharmacist team approach for uncontrolled hypertension. J Gen Intern Med. 1998;13 (11):740-5, November.

27. Borenstein JE, Graber G, Saltiel E, et al. Physician-pharmacist comanagement of hypertension: a randomized, comparative trial. Pharmacotherapy. 2003;23(2):209-16, February.

28. Vivian EM. Improving blood pressure control in a pharmacist-managed hypertension clinic. Pharmacotherapy. 2002;22(12):1533-40, December

29. Sookaneknun P, Richards RM, Sanguansermsri J, Teerasut $\mathbf{C}$. Pharmacist involvement in primary care improves hypertensive patient clinical outcomes. Ann Pharmacother. 2004;38(12):2023-8, December. 